\title{
OM-MADE: an open-source program to simulate one-dimensional solute transport in multiple exchanging conduits and storage zones.
}

\author{
Anne-Julie Tinet ${ }^{1}$, Pauline Collon ${ }^{1, *}$, Camille Philippe ${ }^{1}$, Lorraine Dewaide ${ }^{2}$, and Vincent Hallet ${ }^{2}$ \\ ${ }^{1}$ GeoRessources (Université de Lorraine, CNRS, GeoRessources, F-54000 Nancy, France \\ ${ }^{2}$ University of Namur, Geology Department, Rue de Bruxelles,61, 5000 Namur, Belgium \\ "Corresponding author: pauline.collon@univ-lorraine.fr; Tel.: +333 8372744523
}

\begin{abstract}
OM-MADE (One-dimensional Model for Multiple Advection, Dispersion, and storage in Exchanging zones) is an open-source python code for simulating onedimensional solute transport in multiple exchanging conduits and storage zones in steadystate flow conditions. It aims at helping the interpretation of multi-peaked skewed breakthrough curves (BTCs) that can be observed in tracer tests conducted in karstic systems. OM-MADE is based on the resolution of classical mass conservation equations. In OMMADE, all parallel and exchanging flow zones are divided along the direction of flow into reaches, in which all model parameters are kept constant. The total flowrate may be modified through lateral in and outflows. The solute may also be affected by decay processes either in mobile or immobile zones. Each reach is subdivided into discrete segments of equal length. The partial differential equations can be solved using two second order schemes, one based on an operator-split approach, the other on Crank-Nicholson pondered scheme. A verification is performed against analytical solutions, OTIS software [Runkel, 1998], and the dual-advection dispersion equation (DADE) proposed by Field and Leij [2012]. An application to a tracer test carried out in the karstic area of Furfooz (Belgium) is then performed to reproduce the double-peaked positively skewed BTC that has been observed. It constitutes a demonstration of the software capacities in the case of two reaches and three exchanging zones, among which two are mobile ones and one represents a storage zone. It thus permits to verify numerically the consistency of the conceptual interpretation of the observed BTC.
\end{abstract}

\section{Keywords}

Karsts

Tracer tests

Breakthrough curves

Software

One-dimensional solute transport

\section{INTRODUCTION}

The specific geometries of karstic systems have a huge impact on the underground fluid circulations. In such media, hydraulic connections are difficult to predict with the classical laws describing porous media transport: a more or less porous matrix co-exists with fractures and large open drains of various topologies and sizes. Tracer tests are a common and powerful tool to assess groundwater transfers and get a first-order understanding of a hydrogeological system [e.g., Goldscheider et al., 2003, Perrin and Luetscher, 2008, Goldscheider et al., 2008, Field and Leij, 2012, Mudarra et al., 2014, Dewaide et al., 2016]. Used in karstic settings, they provide direct information on two major points: (i) the existence of a hydraulic connection between two points - generally a sink or swallow hole and a spring - [e.g., Knöll and Scheytt, 2017], and (ii) the time needed for the fluid to travel between these two points [e.g., Morales et al., 2007].

A careful analysis of breakthrough curves (BTCs) provides additional information on the major, and potentially secondary, flows between inlets and outlets [e.g., Smart, 1988, Perrin and Luetscher, 2008]. In particular, asymmetric BTCs with long tails are commonly observed and are generally explained by multiple conduit configurations, or interactions with pools or immobile water zones [e.g., Hubbard et al., 1982, Bencala, 1983, Martin and McCutcheon, 1998, Goldscheider et al., 2003, Bonniver, 2011, Dewaide et al., 2016]. Multi-peaked BTC is a second specific feature that has been reported in some tracer tests carried out in karstic systems [Goldscheider et al., 2008, Dewaide et al., 2018]. Often interpreted as an effect of auxiliary conduits [Smart, 1988, Goldscheider et al., 2008, Perrin and Luetscher, 2008], the presence of large pools in the flow path is also proposed to explain this particular feature [Hauns et al., 1998]. It has been numerically and experimentally reproduced by Field and Leij [2012]. Recently, Dewaide et al. [2018] have provided field measurements in the Furfooz karstic system (Belgium) that show a double-peaked BTC. The Furfooz system is characterized by the presence of a large underground lake, partly segmented into two zones by a vertical wall. The authors have thus proposed a conceptual model of solute transport that would imply a dual-advective transport within the lakes combined with a strong dispersive effect of this storage zone.

If further field investigations should help to check these 
hypotheses, numerical tools could also be used for that purpose. As dispersion is most significant in the flow direction, one-dimensional models have been used to analyse and/or reproduce tracer tests [Goldscheider et al., 2008]. They are generally based on the resolution of the classical AdvectionDispersion Equation (ADE). They permit, through inversion processes, to define average hydrodynamic parameters of underground paths [Hauns et al., 1998, Massei et al., 2006, Goldscheider et al., 2008]. Different software tools have been developed for that purpose. The QTRACER2 program [Field, 2002] is a well-known example. However, such single-flow homogeneous models could not easily assess the influence of immobile flow zones, like pools or eddies, commonly claimed to explain long tail BTCs [e.g., Goldscheider et al., 2003, Birk et al., 2005, Bonniver, 2011]. Different approaches have thus emerged to handle the effect of immobile zones and generate more adaptable tails [Field and Pinsky, 2000, Hauns et al., 2001, Massei et al., 2006, Geyer et al., 2007]. Simulating retention zones by stagnant cells, the approach recently proposed by Morales et al. [2010] provides the optimal number of stagnant cells, and thus, of the retention zone volume to better fit the observed BTCs. In all these approaches, each tracer test provides one BTC and the karstic system can not be discretized along the flow when the tracer is observed at several successive locations. The OTIS program (One-dimensional Transport with Inflow and Storage [Runkel, 1998]) also uses a two-region non equilibrium model allowing to integrate immobile flow zones. Moreover, it permits to discretize the karstic system into several reaches of homogeneous parameters, allowing to model tracer tests with multiple observation points. It has already been used by Dewaide et al. [2016] to model tracer tests carried out in the Han-sur-Lesse karstic system (Belgium) and help their interpretation in term of corresponding conduit geometries. OTIS supposes one main flow zone. However, karstic systems can display particular configurations with auxiliary conduits that divert the solute and then transport it back to the main one. To integrate the effect of auxiliary conduits generating multi-peaked BTCs, multi-dispersion models (MDM: Goldscheider et al. [2008], Field and Leij [2012]) have been soon proposed [Maloszewski et al., 1992, Käss, 1998]. They consist of the superposition of several independent advectivedispersive models, which supposes a complete independence of the flow paths all along the modelled length. To better take into account the interactions that actually exist between the different flow paths, Field and Leij [2012] have proposed a dual-advection dispersion equation (DADE) that revealed to efficiently reproduce multi-peaked BTCs. This model does not allow to discretize the conduits along the flow, nor to combine two exchanging advective-dispersive zones with a storage area, but it is a relevant solution to model unknown parts of the network were the main flow can divide into two conduits before merging back. To simulate more geometrically complex networks, several authors have recently proposed to use pipe flow models [Campbell and Sullivan, 2002, Peterson and Wicks, 2006, Wu et al., 2008, Chen and Goldscheider, 2014, Jeannin et al., 2015, Kaufmann et al., 2016, Vuilleumier, 2018]. Using Manning-Strickler formulae and resolving Saint-Venant equations, EPA's Stormwater Management Model (SWMM, Rossman [2015]) has proved able to reproduce the turbulent flow often observed in high flowrate conditions, and can deal with variably saturated pipes. It is thus used to reproduce and forecast the flow discharge at springs [e.g., Kaufmann et al., 2016, Vuilleumier, 2018], as well as to assess the impact of the con- duit and network geometries on the flow response [Peterson and Wicks, 2006]. In this approach, the network has to be explicitely represented, as well as its dimensions.

In this paper, we present an open-source solution to help a first analysis and simulation of long tail multi-peaked BTCs observed in karstic systems: OM-MADE (One-dimensional Model for Multiple Advection, Dispersion, and storage in Exchanging zones). OM-MADE simulates one-dimensional solute transport along a flow path: it does not require an explicit representation of the conduits, only the length and average cross-sectional area are needed. OM-MADE is based on the resolution of classical mass conservation equations (Section 2 and A). It combines the discretization of the flow path into several reaches and the exchange with immobile flow zones proposed in OTIS [Runkel, 1998]) with the multiple flow zone approach proposed by Field and Leij [2012]. OM-MADE is written in Python, which is a commonly known and easily accessible language. It uses the Numpy library, which permits to optimize the numerical equation resolution. The design has been chosen to facilitate the use by non-expert developers (B). A verification has been performed against analytical solutions, OTIS, and DADE models demonstrating the correct functioning of the proposed solution and allowing to assess its performance (Section 3). The capacities of the software to combine dual-advective-dispersive flow and interaction with immobile water along a flow path discretized into several reaches is demonstrated on the Furfooz area (Section 4).

\section{METHODS}

OM-MADE is an open-source software that simulates onedimensional solute transport. Its specificity is to allow multiple advective-dispersive parallel flow zones, or channels, that can exchange with each others, as well as storage, or immobile, zones (Fig. 1). All zones are identically described, the difference between mobile and immobile regions is done through the input flowrate $Q$, which is nil for immobile - storage - zones. All parallel channels are divided along the direction of flow into reaches, in which all physical model parameters are kept constant.

Linear lateral in/outflow is allowed in the mobile zones following the description by Runkel [1998]. Lateral inflow is described by the inflow linear rate $q_{i n}$ and concentration $C_{i n}$ and may lead to a dilution $\left(C_{i n}<C\right)$ or a concentration $\left(C_{i n}>C\right)$ of the solute. Lateral outflow $\left(q_{\text {out }}\right)$, however, does not impact on the concentration since the outflow concentration is the one of the channel. Lateral in/outflow modifies the flowrate in the channel following equation 1 .

$$
\frac{d Q}{d x}=q_{\text {in }}-q_{\text {out }}
$$

The temporal variation of the flowrate is neglected (steady state). The solute may also been affected by adsorption / decay processes either in mobile or immobile zones.

Considering mass conservation, the general equation of a solute transport in a one-dimensional uniform flow in a zone $p$ that can exchange with other zones $q$ can be written:

$$
\begin{array}{r}
A \frac{\partial C}{\partial t}=-Q \frac{\partial C}{\partial x}+\frac{\partial}{\partial x}\left(A D \frac{\partial C}{\partial x}\right)+q_{i n}\left(C_{i n}-C\right) \\
+\sum_{q \neq p} \alpha_{q p}\left(C_{q}-C\right)-\lambda A C
\end{array}
$$



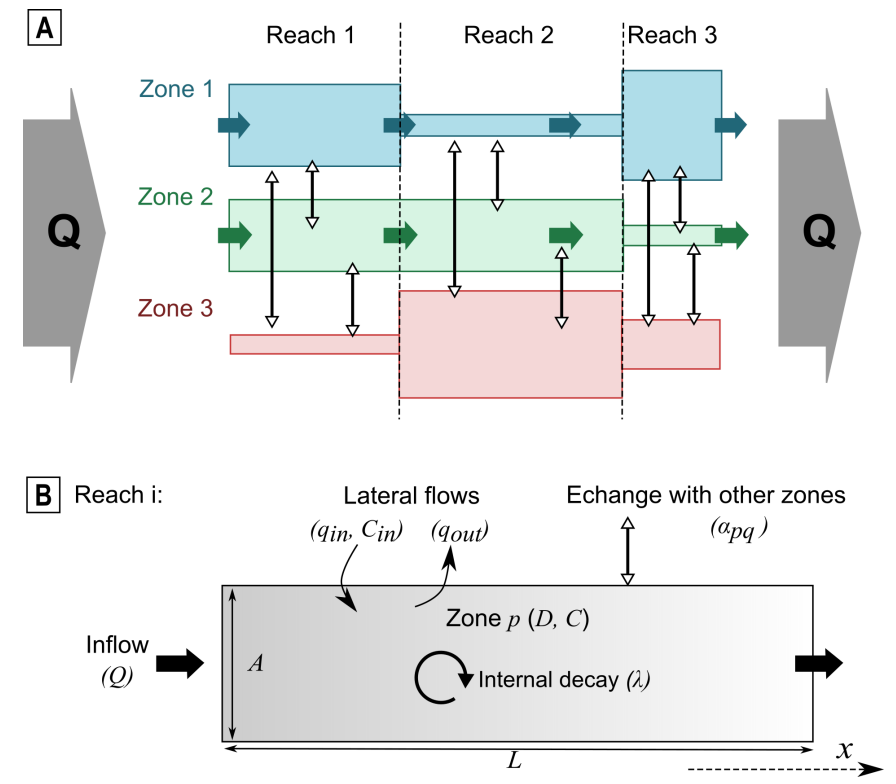

Figure 1 Schematic representation of an OM-MADE model: (A) In this example, two mobile zones (zone 1 and 2) are interconnected with one storage zone (zone 3). The total flowrate $Q$ is preserved all along the flow (steady flow regime). Three reaches are defined to allow longitudinal variations of the system geometrical characteristics. (B) Detailed representation of one reach of a zone $p$ : a reach is defined by a given length $L$, a cross-sectional area $A$, a dispersion coefficient $D$, a solute concentration $C$, linear lateral flows (in/out flowrates and concentration $q_{i n}, q_{\text {out }}, C_{i n}$ ), internal decay (coefficient $\lambda$ ) and exchange(s) with other(s) zone(s) (coefficient(s) $\alpha_{q p}$ ).

where $t(\mathrm{~T})$ designates the time and $x(\mathrm{~L})$ the distance, $A$ $\left(\mathrm{L}^{2}\right)$ is the stream channel cross-sectional area of the zone $p$, $C$ (CU) is the solute concentration in zone $p, Q\left(\mathrm{~L}^{3} / \mathrm{T}\right)$ is the volumetric flowrate across $p, D\left(\mathrm{~L}^{2} / \mathrm{T}\right)$ is the hydrodynamic dispersion coefficient (which combines diffusion and mechanical dispersion), $q_{\text {in }}\left(\mathrm{L}^{2} / \mathrm{T}\right)$ is the lateral inflow rate per unit of distance, $C_{i n}(\mathrm{CU})$ is the solute concentration in lateral inflow, $\alpha_{q p}\left(\mathrm{~L}^{2} / \mathrm{T}\right)$ is the exchange coefficient between the zones $p$ and $q$ multiplied by the exchange surface area, $\lambda\left(\mathrm{T}^{-1}\right)$ is the first order decay coefficient in $p$.

In an immobile - storage - zone, the inflow rate $Q$ is nil. Physically, mechanical dispersion is also nil but molecular diffusion can be considered by setting an adapted value of the hydrodynamic dispersion coefficient $D$, for example in the case of fluoresceine tracing tests: $D \approx 0.64 \times 10^{-9} \mathrm{~m}^{2} / \mathrm{s}$ [Galambos and Forster, 1998].

This global formulation can also be adapted to describe sedimentation zones $\left(Q=q_{i n}=0\right)$ with the following relations:

$$
\begin{gathered}
C=\frac{C_{\text {sed }}}{K_{d}} \\
\alpha_{q p}=\frac{M_{\text {sed }}}{L} \widehat{\lambda} K_{d}
\end{gathered}
$$

where $K_{d}$ (volume/mass unit) is the coefficient of partition, $\widehat{\lambda}$ the decay coefficient, $M_{\text {sed }}$ the mass of available sediments, $C_{\text {sed }}$ the adsorbed concentration on sediments and $L$ the total length of the zone.

To solve the partial differential equation 2, two discretization schemes have been implemented in the OM-MADE software. The first one is based on an operator-split approach (sequential split) for the temporal discretization [Geiser, 2010, Khan and
Liu, 1998]. The second one is similar to the one used in OTIS. Both discretization schemes are detailed in A.

OM-MADE is written in Python v3. The software architecture is described in B. The OM-MADE package is freely available on GitHub as a Python project (https: / / github. com/OM-MADE /OM-MADE). It is provided with examples of applications on the following verification case studies (Section 3 ), as well as an application on the Furfooz karstic area (Section 4).

\section{VERIFICATION AGAINST ANALYTICAL SOLUTIONS AND ALTERNATIVE MODELS}

When developing a numerical solution, its correct functioning should be assessed. This verification of the software also allows understanding the software performance, both regarding computing performance and accuracy. The verification finally showcases the weak points of the numerical solution so as to provide the end-user indicators to use the software in the best conditions. The first set of verifications concerns analytical solutions. Pure diffusion and pure advection allow testing the extreme values of the Peclet number $(P e=|Q d x / A D|)$ which characterizes the transport phenomena in steady-state flow conditions. The analytical Advection-Dispersion Equation (ADE) allows the verification at an intermediate Peclet and corresponds to the most common application. The second set of verifications concerns numerical comparison to other software. Such verifications allow to check the capability of the software's added functionalities compared to the ADE: multiple flow zones with and without an exchange term (section 3.4), multi-reach, lateral flow, and degradation/adsorption (section 3.5). To compare objectively the OM-MADE results with the reference cases, the Normalized Root Mean Square Error (NRMSE) is computed. All values can be found in the online examples, and main results are given here.

\section{Pure diffusion}

A pure diffusive flow, no flowrate (it is an immobile flow zone) is simulated in a single conduit of $1500 \mathrm{~m}$ length, $1 \mathrm{~m}^{2}$ crosssectional area. The hydrodynamic dispersion coefficient is set to $0.05 \mathrm{~m}^{2} / \mathrm{s}$. Initial concentration is nil, and a constant concentration of $350 \mathrm{mg} / \mathrm{l}$ is injected continuously. The total simulation time is $40 \mathrm{~h}$, space step is $1 \mathrm{~m}$ and time step is $9000 \mathrm{~s}$. Fig. 2 plots the concentration profiles observed along the conduit each $150 \mathrm{~h}$. It is compared to the analytical solution in case of a semi-infinite wall:

$$
C(t)=C_{0} \operatorname{erf}\left(\frac{x}{2 \sqrt{D t}}\right)
$$

with $C_{0}$ the injected concentration and $D$ the hydrodynamic dispersion. Considering that the outlet boundary conditions of the numerical model and of the analytical solution are different, a comparison between the two is only valid when the outlet boundary impact on the solution is negligible, i.e. at short-times. This explains the small differences observed at $x=1500 \mathrm{~m}$, when the tracer arrives at the output location at $t=1200 h$. But still for $t=1200 h$, the Normalised Root Mean Square Error (NRMSE) remains inferior to $0.05 \%$ for both schemes. 


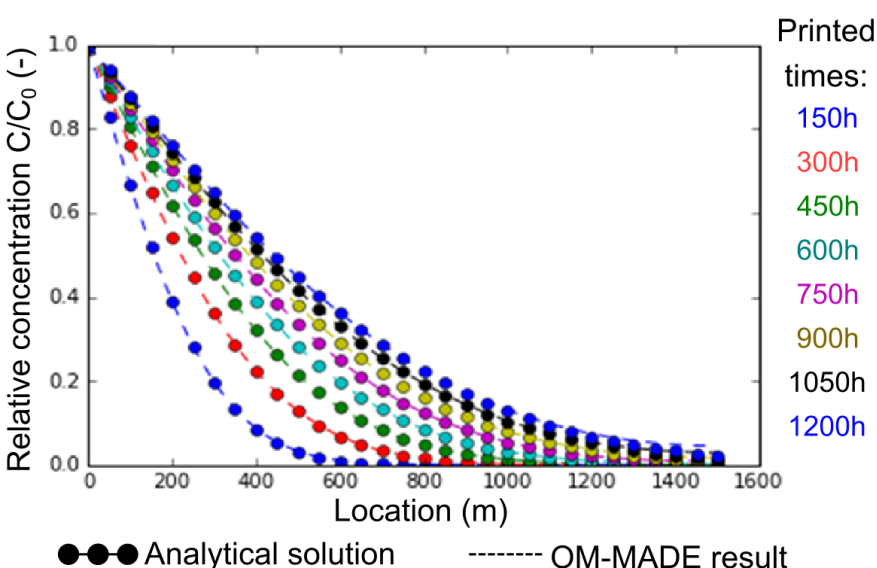

Figure 2 Comparison of OM-MADE result with an analytical solution in the case of a pure diffusive flow. At $t=1200 h$, the tracer arrives at the output location, thus the semi-infinite wall condition is no more valuable and explains the small differences that can be observed with the analytical solution.

\section{Pure advection}

A pure advective flow is simulated in a single conduit of 1500 $\mathrm{m}$ length, $1 \mathrm{~m}^{2}$ cross-sectional area, with a flowrate of 0.01 $\mathrm{m}^{3} / \mathrm{s}$. Initial concentration is nil, and a concentration of 350 $\mathrm{mg} / \mathrm{l}$ is injected during $3 \mathrm{~h}$. The total simulation is $40 \mathrm{~h}$. The simulation time step of $300 \mathrm{~s}$ leads to a Courant number of 3 . As a consequence, the operator-split scheme requires 3 subloops of advection, each with a Courant number of 1 , compared to the Crank-Nicholson scheme. A second simulation time step of $250 \mathrm{~s}$ is used to demonstrate the impact of a Courant number strictly below 1 ( 0.5 for the last sub-loop in the present case) on the behavior of the operator-split scheme. Figure 3 plots the concentration profiles observed along the conduit each 5 $\mathrm{h}$, using operator-split scheme for both time steps, and the Crank-Nicholson scheme for a time step of $300 \mathrm{~s}$.

In all cases, the model reproduces correctly the arrival time of the pollutant step. The computing time in the present cases is around 1 minute on a regular hardware with the operator-split being roughly 1.7 times faster. For the explicit Lax-Wendroff scheme (Figure 3A), the model demonstrates a satisfying behaviour with a NRMSE of the size of rounding error $(0.6 \%)$. This error is generated by the interpolation of the solution between two actual solution points and the beginning and ending of the concentration step rather than by the numerical solution itself. However, when the Courant number is below 1 , which is partly the case when the time step equals 250 $\mathrm{s}$, notable spurious oscillations occur and increase with time (NRMSE going from $1 \%$ at $5 \mathrm{~h}$ to $1.6 \%$ at $40 \mathrm{~h}$ ). Regarding the Crank-Nicholson model, spurious oscillations also occurs and lead to a significant error (NRMSE $=3.6 \%$ at $40 \mathrm{~h}$ ). These oscillations are attenuated through numerical dispersion which also adds to the error. It should be noted that the spurious oscillations are characteristic of second order spatial schemes such as Lax-Wendroff and centred approaches [Lax and Wendroff, 1960, Zheng and Wang, 1999]. Therefore, OM-MADE may not be used in pure advection conditions $(\mathrm{Pe}=\infty)$.

\section{Advection - Dispersion}

A solute transport by advection-dispersion is simulated in the same conduit of $1500 \mathrm{~m}$ length and $1 \mathrm{~m}^{2}$ cross-sectional area,
A Operator-split scheme: Time step $=300 \mathrm{~s}$

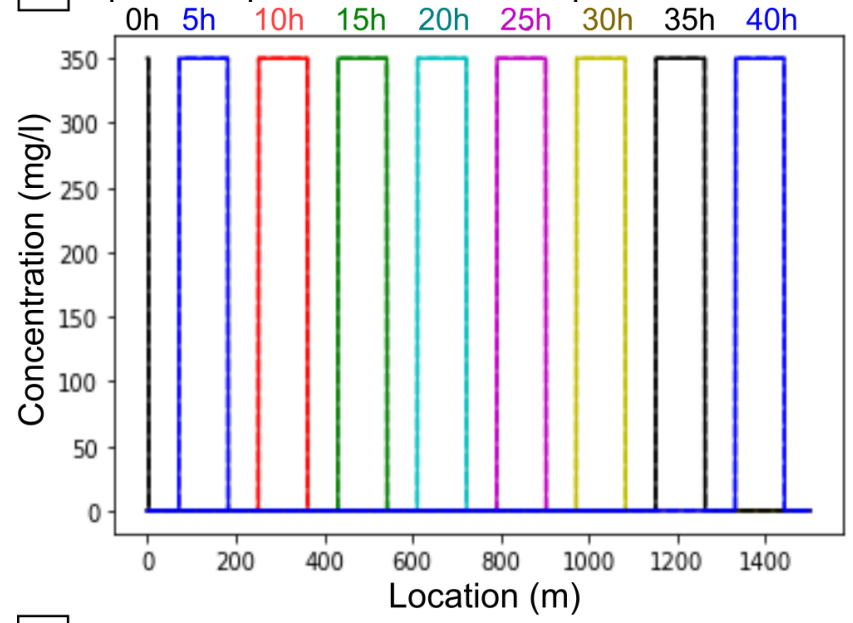

B Operator-split scheme: Time step $=250 \mathrm{~s}$

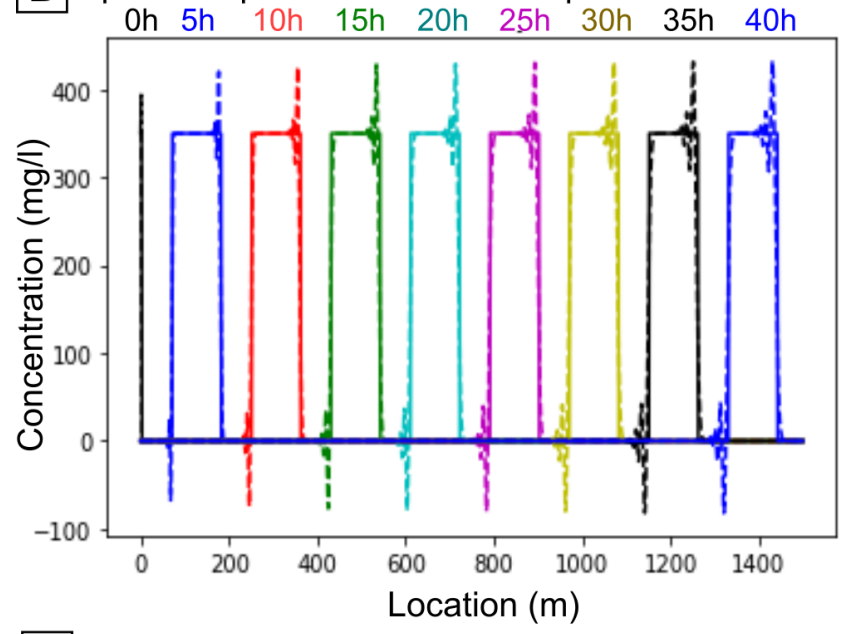

C Crank-Nicholson scheme: Time step $=300 \mathrm{~s}$

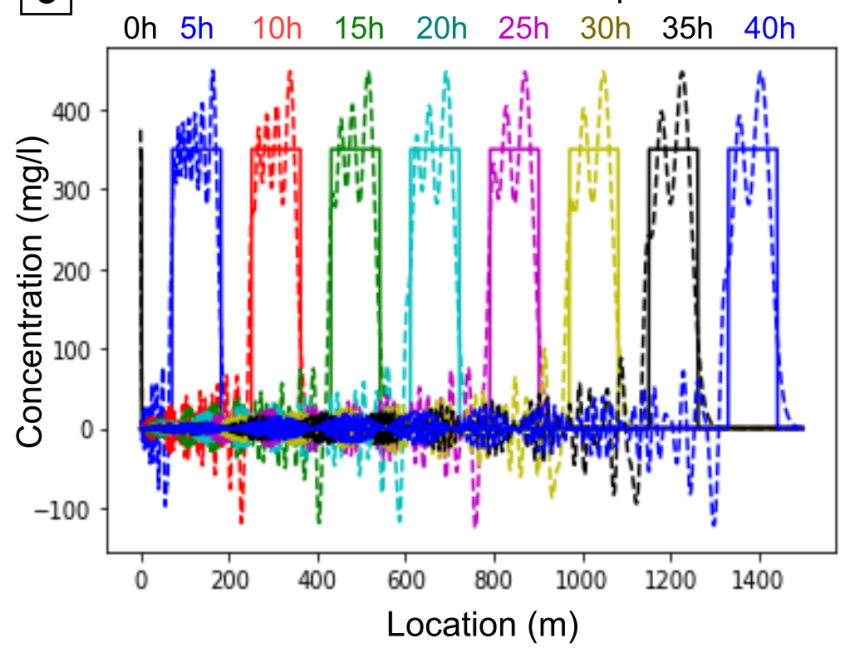

Analytical solution

OM-MADE result

Figure 3 Comparison of OM-MADE results with an analytical solution in the case of a pure advective flow: the concentration profiles are plotted each $5 \mathrm{~h}$ along the conduit. In (A) and (B), OM-MADE uses the operator-split scheme (Lax-Wendroff scheme for advection resolution) with a time step of $300 \mathrm{~s}$ in (A) and $250 \mathrm{~s}$ in (B). In (C) OM-MADE is run using a Crank-Nicholson scheme and a time step of $300 \mathrm{~s}$. 
A Operator-split scheme, $\mathrm{D}=0.05=\mathrm{Pe}=0.2$

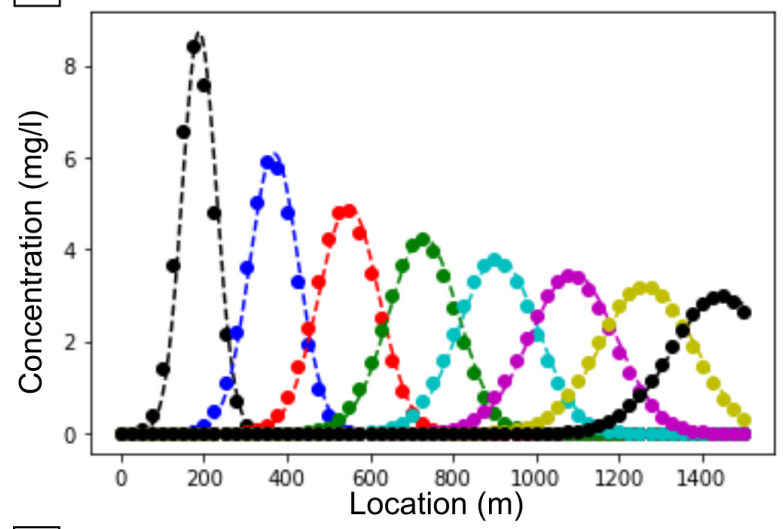

Printed

times:

$5 \mathrm{~h}$

$10 \mathrm{~h}$

$15 \mathrm{~h}$

$20 \mathrm{~h}$

$25 \mathrm{~h}$

$30 \mathrm{~h}$

$35 \mathrm{~h}$

$40 \mathrm{~h}$

B Operator-split scheme, $\mathrm{D}=0.0025 \Rightarrow \mathrm{Pe}=4$

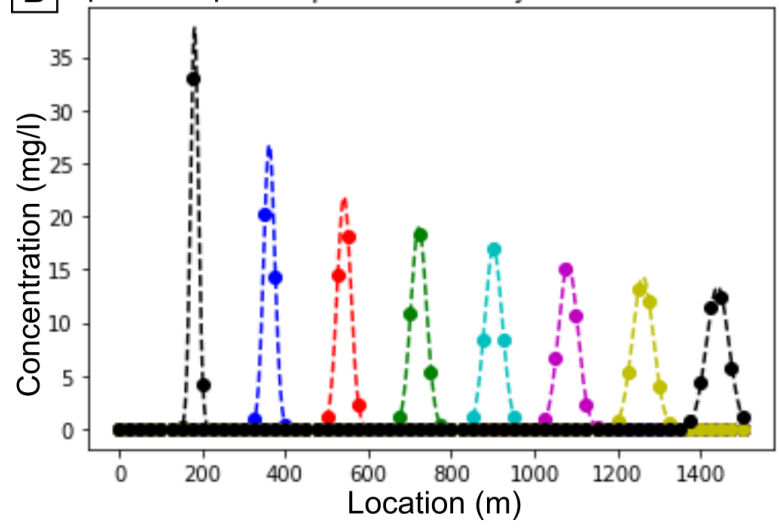

Analytical solution

OM-MADE result

Figure 4 Comparison of OM-MADE results (operator-split scheme) with an analytical solution in the case of advective-dispersive flow. In (A) the hydrodynamic dispersion coefficient $D=0.05 \mathrm{~m}^{2} / \mathrm{s}$ which leads to $\mathrm{Pe}=0.2$. In (B) $D=0.0025 \mathrm{~m}^{2} / \mathrm{s}$ which leads to $\mathrm{Pe}=4$, a value often considered as the usability limit of second order schemes.

with a flowrate $Q=0.01 \mathrm{~m}^{3} / \mathrm{s}$ and a hydrodynamic dispersion coefficient $D=0.05 \mathrm{~m}^{2} / \mathrm{s}$ (leading to $\mathrm{Pe}=0.2$ ) or $D=0.0025 \mathrm{~m}^{2} / \mathrm{s}$ (leading to $\mathrm{Pe}=4$ ). A value of Peclet number of 4 is often considered as the usability limit of second order schemes [Zheng and Wang, 1999]. Initial concentration is nil, and we consider an instantaneous solute pike corresponding to the injection of $M=900 \mathrm{~g}$ of tracer. The total simulation time is $40 \mathrm{~h}$, space step is $1 \mathrm{~m}$ and time step is $360 \mathrm{~s}$. For the simulation, instantaneous injection is not possible to model: the tracer is injected during one time step $d t=360 \mathrm{~s}$. Thus, it corresponds to a concentration $C_{0}=M /(Q * d t)=250 \mathrm{mg} / \mathrm{l}$. Fig. 4 plots the concentration profiles observed along the conduit each $5 \mathrm{~h}$ using the operator-split approach, and compared to its corresponding analytical solution in a semi-infinite media:

$$
C(t)=\frac{M}{A \sqrt{4 \pi D t}} \exp \left(-\frac{(x-U t)^{2}}{4 D t}\right)
$$

with $\mathrm{U}$ the velocity of the fluids, and A the cross-sectional area.

As shown in Fig. 4, the model behaves adequately with a NRMSE of $0.32 \%$ and $0.55 \%$ for the operator-split scheme at time $=40 \mathrm{~h}$ and, respectively, $\mathrm{Pe}=0.2$ and $\mathrm{Pe}=4$. The CrankNicholson solution generates a similar error $(0.34 \%)$ at $\mathrm{Pe}=$ 0.2 but retains a slight oscillatory behavior at $\mathrm{Pe}=4$ (NRMSE $=$ $0.94 \%)$. Therefore for advective-dominant flows, the operatorsplit approach is more advisable. Besides, the limit of $\mathrm{Pe}=4$ is acceptable to use the OM-MADE software.

\section{Dual advection and dispersion: verification against WSADE and DADE solutions}

To validate the model for multiple mobile flow zones we used two examples published in Field and Leij [2012].

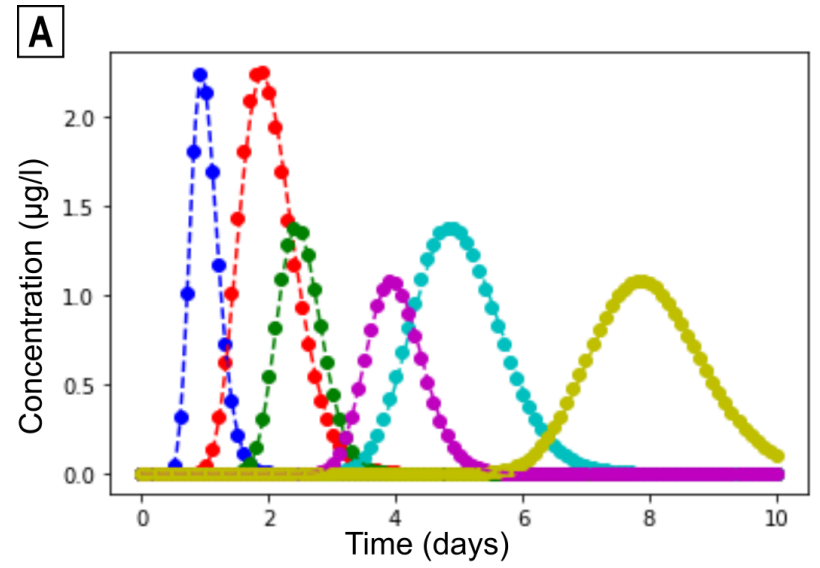

-๑WSADE solution ------- OM-MADE simulation

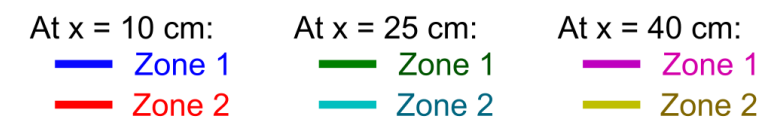

B

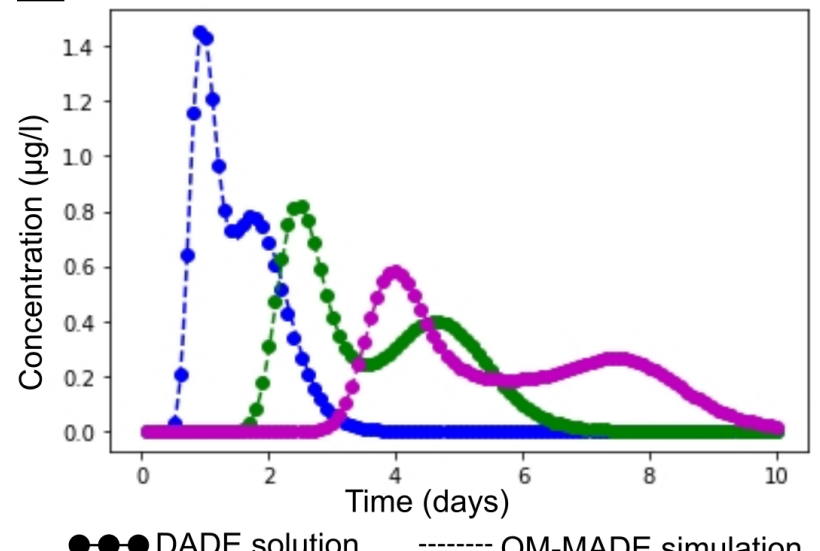

Average concentration at :

$x=10 \mathrm{~cm} x=25 \mathrm{~cm}=40 \mathrm{~cm}$

Figure 5 Simulation of two mobile zones and comparison with solutions of Field and Leij [2012] at three positions: (A) in the case where no exchange are allowed between the two zones (WSADE solution); (B) in the case where exchanges are taken into account between both zones (DADE solution)

The first one considers two mobile flow zones with no exchange. The channels are $200 \mathrm{~cm}$ long, and the concentrations are observed at $10 \mathrm{~cm}, 25 \mathrm{~cm}$ and $40 \mathrm{~cm}$. In the reference paper $q_{i}$ is referred to as "volumetric flow rate in conduit i per total cross-sectional area" (in $\mathrm{cm} / \mathrm{d}$ ) and set as $q_{i}=\theta_{i} v_{i}$. In the application $\theta_{1}=\theta_{2}=0.5$. With both cross-sectional areas equal to $1 \mathrm{~cm}^{2}$, flowrates in conduits are so $Q_{1}=10 \mathrm{~cm}^{3} / d$ and $Q_{2}=5 \mathrm{~cm}^{3} / d$. As the dispersivity $\kappa=0.25 \mathrm{~cm}$, the respective hydrodynamic dispersion coefficients are $D_{1}=2.5 \mathrm{~cm}^{2} / \mathrm{d}$ and $D_{2}=1.25 \mathrm{~cm}^{2} / d$. The total simulation time is $10 \mathrm{~s}$, space step is $0.2 \mathrm{~cm}$ and time step is $0.01 \mathrm{~s}$. An instantaneous solute pike of $12 \mathrm{mg}$ is injected in each channel. In the simulation, we inject during one time step $d t=0.01 \mathrm{~s}$. The corresponding input concentration $C_{0, i}$ for each zone $i$, is deduced by the following relation: $C_{0, i}=m_{i} /\left(q_{i} * d t\right)$ with $m_{1}=m_{2}=6 \mathrm{mg} / \mathrm{cm}^{3}$ the mass injected in each zone. For each zone, it corresponds 
to $C_{0,1}=120 \mathrm{mg} / \mathrm{cm}^{3}$ and $C_{0,2}=240 \mathrm{mg} / \mathrm{cm}^{3}$.

As shown in Fig. 5A, OM-MADE gives similar results than the Weighted-Sum Advection Dispersion Equation (WSADE) solution given by Field and Leij [2012] from the subsolution by Leij and Toride [1995] with NRMSE values at $40 \mathrm{~cm}$ equal to $0.32 \%$ and $0.30 \%$ respectively for the flow zones 1 and 2 using the operator-split approach, and $0.30 \%$ and $0.28 \%$ using Crank-Nicholson.

The second example is the same than the first one, except that an exchange is effective between both mobile zones. The exchange coefficient applied in Field and Leij [2012] is equal to $0.05 \mathrm{~d}^{-1}$, which corresponds in OM-MADE to $\alpha_{1-2}=$ $0.1 \mathrm{~cm}^{2} / d$. Fig. 5B shows that OM-MADE gives similar results than the DADE approach for two exchanging mobile zones with NRMSE at $40 \mathrm{~cm}$ of $0.13 \%(0.12 \%)$ using the operator-split (Crank-Nicholson) approach.

\section{Multi-reaches single flow with storage zone or degradation rate: verification against OTIS}

To test the capacity of our software to model single mobile zones discretized into several reaches and exchanging with storage zones, we compare it to the results obtained with OTIS to simulate a conservative transport in a stream with immobile zones (Application 1 in Runkel [1998]). This simulation has been itself validated against field measurements of a chloride tracer test in Uvas Creek, a small pool-and-riffle stream in northern California (US) [Bencala and Walters, 1983].
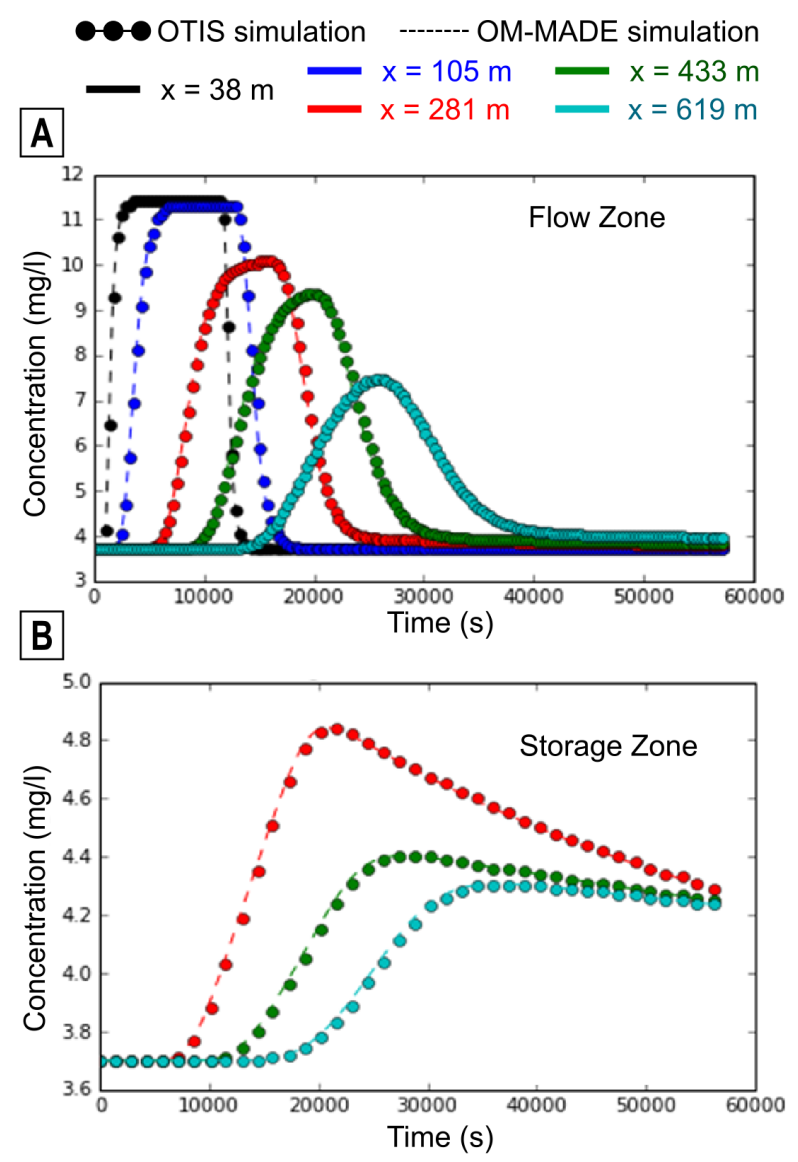

Figure 6 Simulation of BTCs in the case of multi-reach single flow with storage: the domain is divided in 5 reaches, one mobile zone exchanges with storage zones in the reaches 3,4 , and 5 . Simulated concentrations with OTIS and OM-MADE: (A) in the flow zone and (B) in the storage zones.
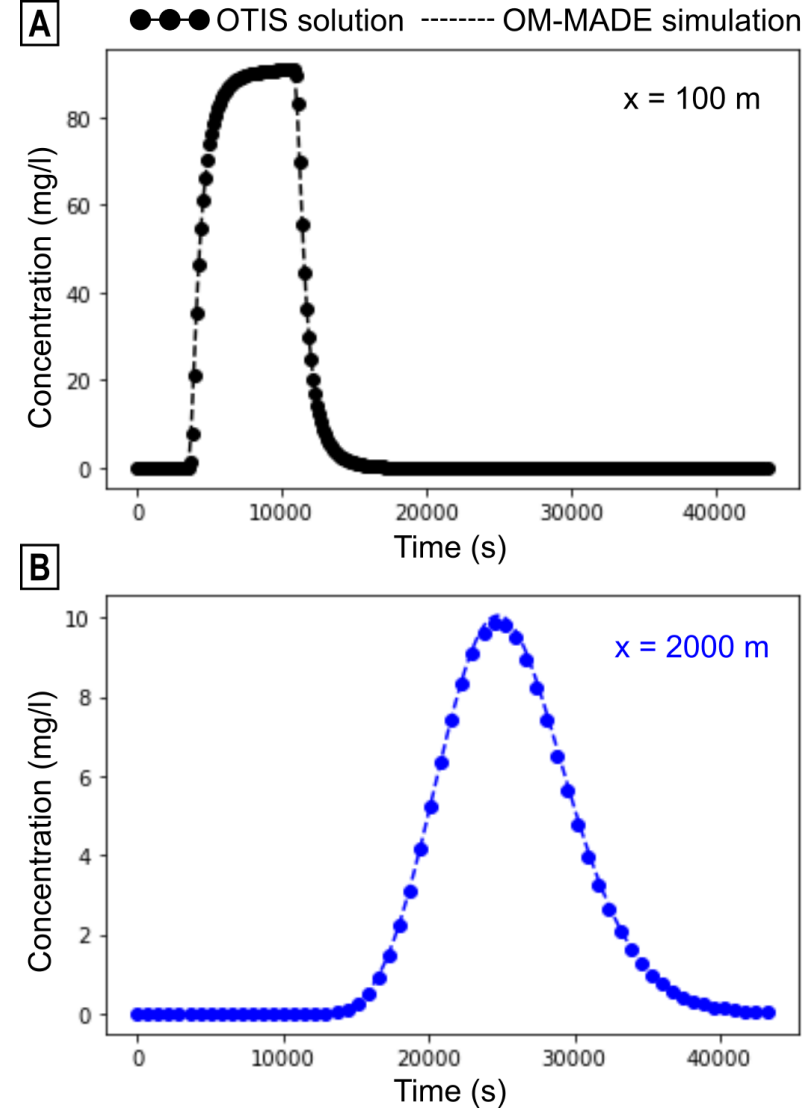

Figure 7 OM-MADE results compared to OTIS solution in the case of transport with first-order decay.

The main stream is represented by a mobile zone with a constant flowrate of $Q=0.0125 \mathrm{~m}^{3} / \mathrm{s}$. Pools are modelled by exchanging mobile zones. The stream is characterized by an initial concentration equals to $3.7 \mathrm{mg} / \mathrm{l}$. The experiment consisted in the injection during $3 \mathrm{~h}$ of chloride at a constant rate of $11.4 \mathrm{mg} / 1$ starting from $8.25 \mathrm{~h}$ for the reference experiment. In our simulation, this initial period is skipped, and the injection is started at $540 \mathrm{~s}$, and thus ends at $11340 \mathrm{~s}$. The total simulation time is $24 \mathrm{~h}$, which corresponds in our simulation to $56700 \mathrm{~s}$. The time step is $180 \mathrm{~s}(=0.05 \mathrm{~h})$, the space step is $1 \mathrm{~m}$, and the concentrations are printed at 5 locations: $38,105,281,433$, and $619 \mathrm{~m}$ from the injection point, corresponding to the five sampling points and the exact limit of the reaches. The domain is divided into 5 reaches whose characteristics are given in Table 1 . The reaches 3, 4, and 5 are characterized by the presence of pools. To reproduce the increasing flow in the downstream direction, lateral inflows are introduced in reaches 3,4 , and 5 . For the sake of comparison and unlike in Runkel [1998], interpolation of the results in between calculated points is allowed in the OTIS solution. All parameters are the same in OM-MADE and OTIS, except for the exchange coefficients which are not defined the same way (Table 1). For homogeneity purposes (Eq. 11), we defined indeed the exchange coefficient between two zones as a value expressed in $\left[\mathrm{m}^{2} / \mathrm{d}\right]$. In OTIS, the exchange coefficient is expressed in $d^{-1}$ and defined as: $\alpha_{\text {OTIS }}=\alpha_{O M-M A D E} / A$, where $\mathrm{A}$ is the cross-sectional area of the mobile zone. Results show a very good fitting with observation at the five observation locations (Fig. 6) with NRMSE in the flow zone of around 0.13\% for the operator-split approach and $0.17 \%$ for Crank-Nicholson as well as in the storage zone with NRMSE of $0.02 \%$ for both schemes. 
Table 1 Parameters of the OM-MADE simulation for multi-reach single flow with storage. These are based on the ones realized with OTIS by Runkel [1998] for the tracer tests by Bencala and Walters [1983] in Uvas Creek.

\begin{tabular}{cccccccccccc} 
& Exchange & \multicolumn{4}{c}{ Mobile zone (Main Stream) } & \multicolumn{3}{c}{ Storage Zone (Pools) } \\
\hline & $\begin{array}{c}\alpha_{1,2} \\
\left(\mathrm{~m}^{2} / \mathrm{s}\right)\end{array}$ & $\begin{array}{c}\mathrm{A} \\
\left(\mathrm{m}^{2}\right)\end{array}$ & $\begin{array}{c}\mathrm{D} \\
\left(\mathrm{m}^{2} / \mathrm{s}\right)\end{array}$ & $\begin{array}{c}q_{\text {in }} \\
\left(\mathrm{m}^{2} / \mathrm{s}\right)\end{array}$ & $\begin{array}{c}q_{\text {out }} \\
\left(\mathrm{m}^{2} / \mathrm{s}\right)\end{array}$ & $\begin{array}{c}C_{\text {in }} \\
(\mathrm{mg} / \mathrm{l})\end{array}$ & $\begin{array}{c}\mathrm{A} \\
\left(\mathrm{m}^{2}\right)\end{array}$ & $\begin{array}{c}\mathrm{D} \\
\left(\mathrm{m}^{2} / \mathrm{s}\right)\end{array}$ & $\begin{array}{c}q_{\text {in }} \\
\left(\mathrm{m}^{2} / \mathrm{s}\right)\end{array}$ & $\begin{array}{c}q_{\text {out }} \\
\left(\mathrm{m}^{2} / \mathrm{s}\right)\end{array}$ & $\begin{array}{c}C_{\text {in }} \\
\left(\mathrm{mg}^{2} / \mathrm{l}\right)\end{array}$ \\
\hline Reach 1 & 0 & 0.30 & 0.12 & 0 & 0 & 3.7 & 0.05 & 0 & 0 & 0 \\
\hline Reach 2 & 0 & 0.42 & 0.15 & 0 & 0 & 3.7 & 0.05 & 0 & 0 & 0 \\
\hline Reach 3 & $1.08 \mathrm{e}-5$ & 0.36 & 0.24 & $4.545 \mathrm{e}-6$ & 0 & 3.7 & 0.36 & 0 & 0 & 0 \\
\hline Reach 4 & $4.10 \mathrm{e}-6$ & 0.41 & 0.31 & $1.974 \mathrm{e}-6$ & 0 & 3.7 & 0.41 & 0 & 0 & 0 \\
\hline Reach 5 & $2.34 \mathrm{e}-5$ & 0.52 & 0.40 & $2.151 \mathrm{e}-6$ & 0 & 3.7 & 1.56 & 0 & 0 & 0 \\
\hline
\end{tabular}

A second comparison with OTIS was performed to validate the simulation of transport with first-order degradation rate (Application 3 in Runkel [1998]). It illustrates a hypothetical problem of a single reach - single flow zone transport of a decaying substance, which has been analytically solved in Runkel [1996]. The simulation is thus characterized by one mobile zone of $2200 \mathrm{~m}$ long and $1 \mathrm{~m}^{2}$ cross-sectional area, with an initial null concentration and constant flowrate $Q=0.1 \mathrm{~m}^{3} / \mathrm{s}$. Its hydrodynamic dispersion coefficient is $D=5 \mathrm{~m}^{2} / \mathrm{s}$. The unique reach is discretized in $10 \mathrm{~m}$ cells, and the concentrations are observed at $100 \mathrm{~m}$ and $2000 \mathrm{~m}$. The simulation lasts $12 \mathrm{~h}(=43200 \mathrm{~s})$ with a time step $d t=144 \mathrm{~s}$. The decaying substance is injected during 2 hours starting at $t=3600 \mathrm{~s}$ with a constant input concentration $C_{0}=100 \mathrm{mg} / \mathrm{l}$. The degradation rate is $\lambda=1.10^{-4} s^{-1}$. The results obtained with OM-MADE are, again, similar to those obtained with OTIS and validated against analytical solution by Runkel [1998] (Fig. 7), with a NRMSE of $0.46 \%$ for the operator-split approach at $2000 \mathrm{~m}$, and $0.31 \%$ for the Crank-Nicholson approach. It should also be noted that this is the only verification case, among those presented, when the Crank-Nicholson approach is more efficient than the operator-split approach. But it should also be noted that we are comparing with the data from OTIS which uses a Crank-Nicholson scheme.

\section{APPLICATION ON THE FURFOOZ KARSTIC SYSTEM}

The karstic system of Furfooz is located in the South of Belgium, near Dinant. The Furfooz karst has developed in the limestones of Carboniferous Dinantian, more specially in the Waulsortian mudmounds [Dewaide et al., 2014]. The network mainly consists in conduits with flooded cross-sections of 1-2 $\mathrm{m}^{2}$ in moderate flow conditions, and has the specificity to cross two successive underground lakes (Fig. 8). It constitutes an underground system of approximately $1.2 \mathrm{~km}$ length which catches partially the Lesse River and returns the water back to surface through a diffusive resurgence. While a large part of the system has been explored, the downstream part of the lakes remains unknown, as well as the first $70 \mathrm{~m}$ downstream the swallow hole.

A tracer test has been performed, consisting in the injection of $200 \mathrm{~g}$ of sulforhodamine B at the swallow hole, located 210 $\mathrm{m}$ upstream the lakes, during stable low flow conditions. Several flow measurements were performed during the tracer test at several locations and times, and provide integrated values that vary in the underground network between $5.5 \mathrm{l} / \mathrm{s}$ to 5.97 1/s from the Trou qui fume to the Galerie des Sources [Dewaide, 2018]. At the swallow hole, the flowrate was, however, estimated around 3.5-3.8 1/s, suggesting that around $21 / \mathrm{s}$ are penetrating the karstic system through diffuse entries before the main karstic conduit of the Trou qui fume. Water samples were analysed on site using field fluorometers at two locations: in the Trou qui fume, and in the Galerie des Sources (Fig. 8). The Trou qui fume is the first explorable part of the Furfooz karstic system. It is preceded by an impenetrable zone, probably tortuous and highly fractured, right after the swallow hole, that hydrogeologists and speleologists consider to represent a flow path of approximately $70 \mathrm{~m}$ long. Then, in the Trou qui fume, the water is mainly confined in a single conduit of approximately $140 \mathrm{~m}$ long, only partly flooded and easy of access, that ends in the first lake. These two zones represent a first section of approximately $210 \mathrm{~m}$ that links the swallow hole to the lake. Located in the middle of this single conduit, the first sampling point is estimated to be $150 \mathrm{~m}$ downstream the swallow hole.

The water flows a minimum distance of $150 \mathrm{~m}$ through the lakes before penetrating an unexplored conduit part to the $\mathrm{Ga}$ lerie des Sources. Inside the Galerie des Sources, the second sampling point is considered by hydrogeologists and speleologists to be located approximately $410 \mathrm{~m}$ downstream the lakes (and so, $770 \mathrm{~m}$ downstream the swallow hole). It should be noted that these lengths are approximative lengths based on map study. They could potentially be under-estimated.

At the first sampling point, the tracer recovery results in a classical single peaked BTC with a slight asymmetry. Downstream the lakes at the Galerie des Sources, tracer recovery results in a skewed dual-peaked BTC. Further investigations have conducted Dewaide [2018] to propose a conceptual model of the system that explains this BTC by a combination of a storage zone effect and a dual-advective flow zone within the lake area. Thus, analysing this BTC with OM-MADE seems appropriate.

Fig. 9 depicts the OM-MADE fit to the BTC observed at the Trou qui fume and the Galerie des Sources. The system is represented by a succession of 2 reaches, corresponding to both monitored zones: (i) the first one represents the first part of $210 \mathrm{~m}$ long, which is observed at the Trou qui fume, $150 \mathrm{~m}$ downstream the injection point; (ii) the second reach corresponds to a transport distance of $570 \mathrm{~m}$ downstream the lakes and illustrates the combined effect of the lakes and of their downstream part until the Galerie des sources, located at a supposed distance of $770 \mathrm{~m}$ downstream the injection point. Note that to avoid eventual boundary effects, the reach terminates further than the observation point location. In this application, the intermediary sampling sites (sites 2 and 3 in Dewaide et al. [2018]) are not considered. Indeed, the probes were located at the surface of the lakes, and do not account for an average behaviour of the water lake volume: later field experiments [Dewaide, 2018] have demonstrated that these probes were only registering dispersion inside the lake while an advective quicker transport occurred deeper in it. 

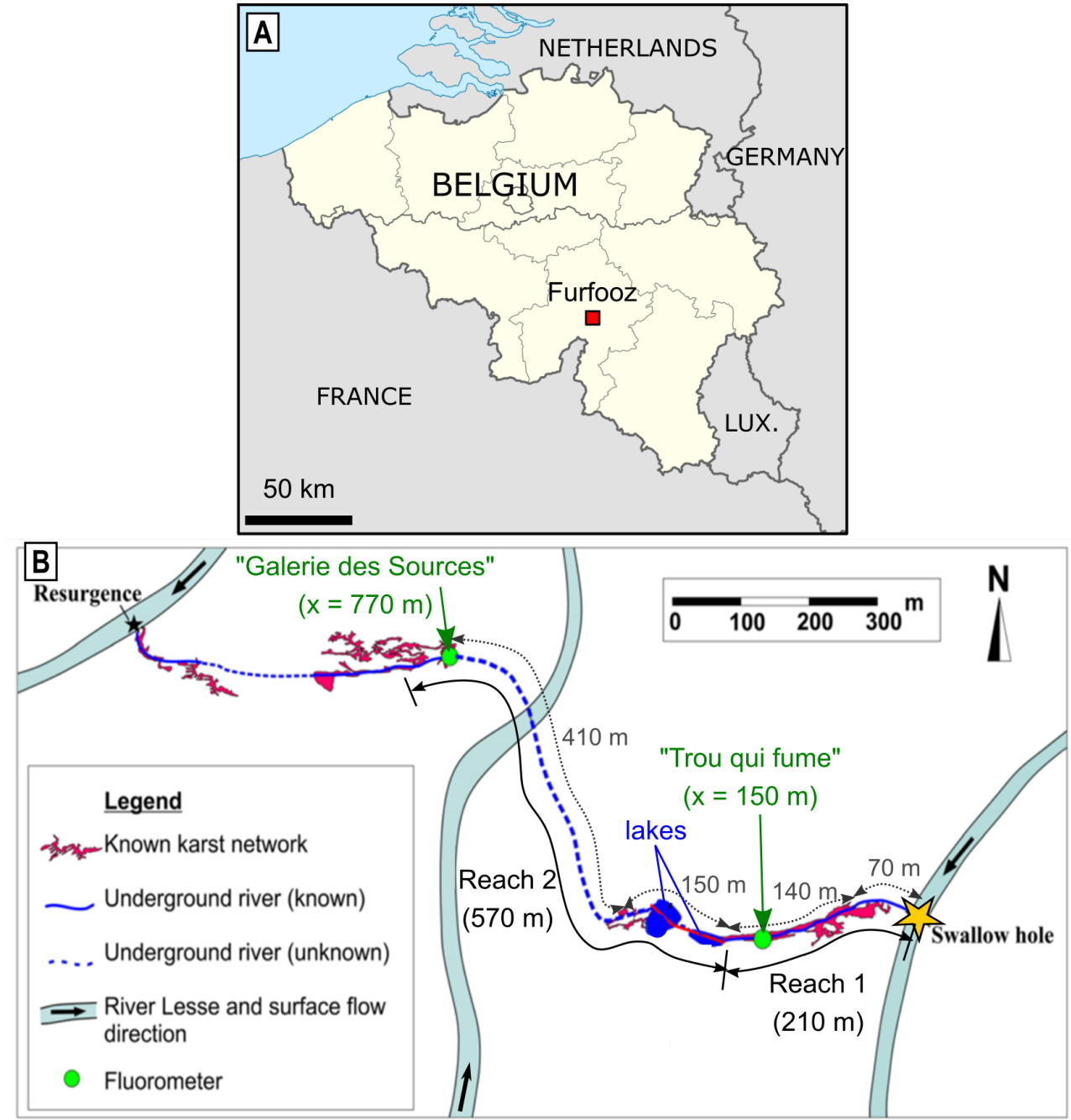

Figure 8 The Furfooz karstic system and its numerical representation. Two sampling locations are considered : the Trou qui fume and the Galerie des Sources. The system is approximated by two reaches: (i) the first one represents a first mainly advective part ; (ii) the second reach represents the ensemble made by the lakes and their unexplored downstream part. 
The first BTC expresses a quick (in less than 3 hours) and mainly advective transport of the tracer. Thus, to avoid numerical dispersion while keeping reasonable computational times to simulate a tracer test of $600 \mathrm{~h}(=2160000 \mathrm{~s})$, we use a space step of $2.5 \mathrm{~m}$ and a time step of $360 \mathrm{~s}$. With those numerical parameters, the simulation takes $4 \mathrm{~min} 30 \mathrm{~s}$ on a standard laptop with 8 Go RAM and a $2.60 \mathrm{GHz}$ Intel(R) Core(TM) Processor. In this model, which largely approximates the natural behaviour and uses a steady flow regime, we consider a total mean discharge of $Q=5.7 \mathrm{l} / \mathrm{s}$. Given the observations at the swallow hole, we decided to distribute this discharge between the two mobile zones as followed: $3.7 \mathrm{l} / \mathrm{s}$ is considered to penetrate in the first mobile zone, while zone 2 is characterized by an input discharge of $2 \mathrm{l} / \mathrm{s}$. The initial concentration of the water is nil, and at $t=0$ an injection of $200 \mathrm{~g}$ of the tracer is performed in zone 1 only, which, applied to our time step and with an input flowrate of $3.7 \mathrm{l} / \mathrm{s}$, corresponds to an input concentration of $C_{1}=150.15 \mathrm{mg} / \mathrm{l}=150150 \mathrm{ppb}$ during the first $360 \mathrm{~s}$. The input concentration is nil in zone 2.

To illustrate the fact that all water is drained by a single conduit in the main part of the first reach, and especially where the sampling is performed, we have decided to impose almost the same flowrate $v_{i}$ in both mobile zones by an adapted choice of the corresponding cross-sectional areas $A_{i}\left(A_{2} \simeq Q_{2} / Q_{1} \times A_{1}\right)$. We chose to distribute the coefficient effects by using equal values in both zones. The first order decay coefficients $\lambda$ express the probable sorption of the sulfhorhodamine, even if it is not rigorously a sorption effect that is numerically reproduced (no
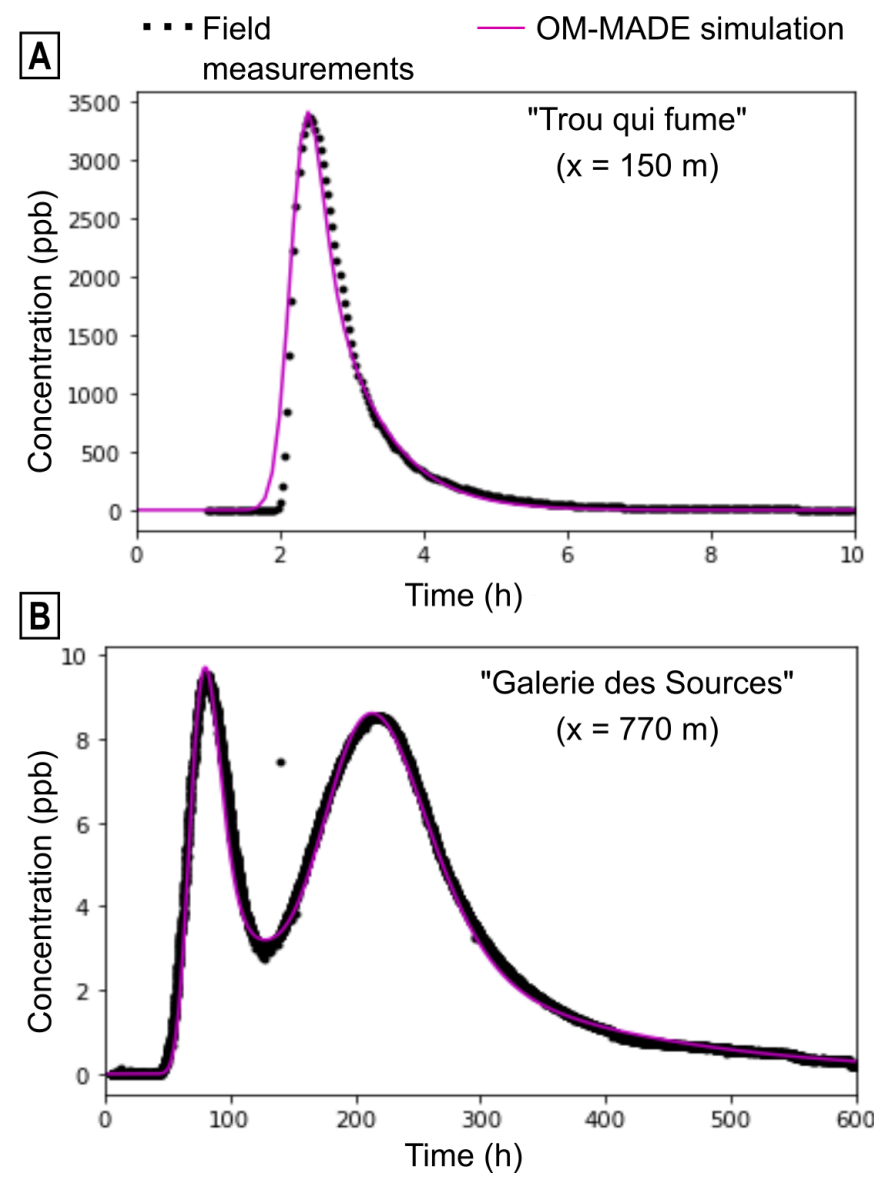

Figure 9 OM-MADE simulated BTC fit to a tracer test conducted in Furfooz. The first site, named "Trou qui fume" is located $150 \mathrm{~m}$ downstream the swallow hole while the second site, the "Galerie des Sources" is located $770 \mathrm{~m}$ downstream the injection point. consideration of exchange surface or relative concentration). Sabatini [2000] demonstrated, indeed, that sulforhodamine B tends to sorb on positively charged limestone surfaces, more than uranine. This has also been observed during a multi-tracer test by Geyer et al. [2007]. In Furfooz, the first part of the underground network is characterized by an important amount of muddy material and a limited tracer recovery has been observed at both sites: a quick integration of the BTCs indicates, when considering a mean discharge of $5.7 \mathrm{l} / \mathrm{s}$, a restitution of around $35 \%$ at the Trou qui fume and $19 \%$ at the Galerie des sources [Dewaide, 2018].

Introducing a small storage zone is necessary to reproduce the BTC asymmetry. This could be related to the unknown part, in the first $70 \mathrm{~m}$ of the system, probably combined with an effect of the small pools and of the variations of the underground stream geometry all along the karstic system, as it has been demonstrated on other karstic sites [Hauns et al., 2001]. In the second reach, a partial independence of both mobile zones is set thanks to a lowest exchange coefficient, and the cross-sectional areas of both mobile zones are not linked any more.

With these input constraints, the different parameter values were manually tuned to fit the two measured BTCs. The resulting set of parameters, presented in Table 2, represent an average behaviour of the two parts of the system, with a given conceptual scenario. They demonstrate the capacity of OM-MADE to model one-dimensional solute transport in mutiple exchanging flow and storage zones with a multi-reach discretization.

\section{DISCUSSION AND CONCLUSION}

OM-MADE has been created as an answer to field hydrologists who could not represent their observed breakthrough curves using easily available and usable software (in this case OTIS and DADE) and needed to model more complex interactions. OM-MADE combines advantages of the OTIS software - a discretization of the flow path into several homogeneous reaches and exchanges with immobile flow zones - and the DADE solution - multiple exchanging mobile zones. It provides so a flexible solution to simulate one-dimensional transport in the case of multiple exchanging mobile and immobile flow zones. Such configurations are, indeed, often suggested to explain multi-peaked BTCs observed when performing tracer tests in karstic systems. It also allows to segment the domain of interest into several reaches of constant model parameters, which is useful to represent the different parts of a karst network that field investigation can reveal, especially when multi-sampling sites are used.

OM-MADE has been tested to simulate a real tracer test performed in Furfooz (Belgium), allowing to demonstrate its potential and also its limits. By modelling a one-dimensional transport, OM-MADE simplifies a complex reality and, as other models, OM-MADE is parametrised by different variables that can not all be measured on the field (e.g., the exchange coefficients, or even the average cross-sectional area of each reach). To reproduce a double-peaked BTC, it was necessary to impose different relative cross-sectional areas, and thus flow rates, in both mobile zones. In the Furfooz application, we have arbitrarily decided to enlarge the second mobile zone, but it has to be reminded that at the end of the first reach, the water has mixed between both conduits, and thus the tracer concentration is the same in both mobile zones. As a consequence, 
Table 2 Parameters of the OM-MADE simulation for modelling one tracing test carried out in the Furfooz karstic system : the system is described by a model with multi-reaches dual-mobile zones with storage. Lateral flows $\left(q_{\text {lat }}\right.$ and $\left.C_{\text {lat }}\right)$ are nil. The simulation is performed with a spatial step $d x=2.5 \mathrm{~m}$ and a time step $d t=360 \mathrm{~s}$. A total mass of $200 \mathrm{~g}$ of sulforhodamine B is injected at $t=0$ in zone 1 .

Reach 1: 0 - $210 \mathrm{~m}$

\begin{tabular}{|c|c|c|c|c|c|c|}
\hline & A & $\mathrm{D}$ & $\lambda$ & \multirow{2}{*}{\multicolumn{3}{|c|}{$\begin{array}{l}\text { Exchange coefficients } \alpha_{i j}\left(\mathrm{~m}^{2} / \mathrm{s}\right) \\
\text { zone } 1 \text { zone } 2 \quad \text { zone } 3\end{array}$}} \\
\hline & $\left(m^{2}\right)$ & $\left(\mathrm{m}^{2} / \mathrm{s}\right)$ & $(1 / s)$ & & & \\
\hline Zone $1(Q=3.7 L / s)$ & 0.217 & 0.014 & $1.25 \mathrm{e}-4$ & 0 & $1 \mathrm{e}-2$ & $2.2 \mathrm{e}-5$ \\
\hline Zone $2(Q=2 L / s)$ & 0.116 & 0.009 & $1.25 \mathrm{e}-4$ & $1 \mathrm{e}-2$ & 0 & $2.2 \mathrm{e}-5$ \\
\hline \multirow[t]{4}{*}{ Zone 3 (Storage) } & 0.063 & $0.6 e-9$ & 0 & $2.2 \mathrm{e}-5$ & $2.2 \mathrm{e}-5$ & 0 \\
\hline & \multicolumn{6}{|c|}{ Reach 2: $210-780 \mathrm{~m}$} \\
\hline & A & $\mathrm{D}$ & $\lambda$ & \multirow{2}{*}{\multicolumn{3}{|c|}{$\begin{array}{l}\text { Exchange coefficients } \alpha_{i j}\left(\mathrm{~m}^{2} / \mathrm{s}\right) \\
\begin{array}{ll}\text { zone } 1 \quad \text { zone } 2 & \text { zone } 3\end{array}\end{array}$}} \\
\hline & $\left(m^{2}\right)$ & $\left(m^{2} / s\right)$ & $(1 / s)$ & & & \\
\hline Zone $1(Q=3.7 L / s)$ & 1.90 & 0.015 & $9.4 \mathrm{e}-7$ & 0 & $1 \mathrm{e}-7$ & $9.8 e-6$ \\
\hline Zone $2(Q=2 L / s)$ & 2.88 & 0.007 & $4 e-8$ & $1 \mathrm{e}-7$ & 0 & $8.5 e-7$ \\
\hline Zone 3 (Storage) & 4 & $0.6 e-9$ & $2 \mathrm{e}-7$ & $9.8 e-6$ & $8.5 \mathrm{e}-7$ & 0 \\
\hline
\end{tabular}

another fit could probably be done by accelerating the flow in the second zone rather than in the first one. Also, the flowrate could be divided differently between the two mobile zones of this reach. Thus, the main interest of such approach, is to test numerically the consistency of a conceptual representation of the natural system. In this simulation, the long tail observed at the Galerie des Sources is the effect of a large storage zone that interacts with both mobile zones, which is consistent with field observations and the existence of the lakes. It also shows that the observed dual-peaked skewed BTC could be explained by two mobile zones exchanging with a storage zone in the part of the karst between the lakes and the Galerie des Sources. This global behaviour does not imply a more precise interpretation : the dual-advective exchanging zones could be an effect of the lakes or an expression of a local auxiliary conduit that diverts the solute transport and then transports it back to the main conduit. More field investigations should now be performed to precise the exact functioning of the Furfooz system. A recent discovery of a conduit between the lakes and the Galerie des Sources will certainly help in that purpose.

Regarding the number of calibration parameters, the more complex the model is (i.e., the higher the number of reaches and flow zones) the more parameters are required. For the endusers, it is advisable to start from the simplest model and, if necessary, to increase complexity. For instance, in Furfooz, a two zone approach (either mobile-immobile or mobile-mobile) was insufficient to correctly describe the measured breakthrough curve. For this specific case, OM-MADE offers the solution to increase progressively the complexity while remaining a very basic solution. However, especially considering increased model complexity, it is to be expected that the calibration is non-unique. In OM-MADE, the values of the various parameters have to be set by a try-and-error approach, which can become a long and difficult task as the number of reaches increase. An obvious improvement should be to implement an automated parameter estimation process, for example by minimizing the squared differences between the simulated and observed concentrations. Nevertheless, such functionality should also allow to fix some of these parameters which, depending on the field case that is studied, can be already known (e.g. cross-sectional areas of some conduits, nil exchanging coefficients, ...), or stacked by the field knowledge, which should be appreciated in such under-constrained problems.

OM-MADE only considers steady-sate conditions for flow (no temporal variation of the flow rate). It should be noted that, in the field, monitoring the flow rate along time can be very problematic in some hardly accessible conduits. For instance, in Furfooz, only a time-averaged value could be measured. During short-distance - and thus short-time - tracer-tests, steady state conditions can be an acceptable approach. But it would be an obvious limitation as soon as precipitations, and thus, floods, occur. Adapting OM-MADE to non-steady conditions is an interesting perspective. Another interesting avenue would be to use pipe-flow models like SWMM, and adapt them to handle immobile flow zones and exchange between conduits.

OM-MADE uses an operator-split approach solving the advective part using a second order Lax-Wendroff scheme with explicit temporal resolution. This choice has been made to limit the numerical dispersion. Therefore, the issue of numerical dispersion is not occurring (or little) in our method. However, oscillatory behaviour remains in specific conditions: oscillatory behaviour is a well-known drawback of second order methods such as Lax-Wendroff or centred scheme in pure advection conditions. It should be noted that when Courant number is strictly equal to one (or is an integer) there is almost no oscillation in the operator-split solution. Following Zheng and Wang [1999], the limit of grid Peclet number of 4 is advised for good use of the OM-MADE solution. In order to limit both numerical dispersion and oscillatory behaviour, it would be necessary to use higher-order schemes such as the 3rd order TVD (TotalVariation-Diminishing method). This was not implemented in the software, but could be an obvious perspective.

In order to provide a better flexibility to the end-user and easy comparison, OM-MADE allows the end-user to choose between the operator-split Lax Wendroff explicit (advection) - implicit (dispersion and exchange) or a centred Crank-Nicholson solution. The explicit solution is faster than implicit or CrankNicholson solution for the same time step since it does not require the computationally expensive solving of a linear system. However, the time step is limited to satisfy the CFL condition. Therefore, when the simulation time step is much larger than the time step required for satisfying the CFL, the explicit solution lacks computing performance. A larger simulation time step leads to a loss in accuracy, especially for the advection. In 
multi-reach conditions, or when cross-sectional flow exists, the calculation of the CFL and therefore the advection time step, is constrained by the maximum Courant number. However, the calculation of the CFL is independent for each conduit since there is no coupling in the advection part.

OM-MADE is written in Python, which, compared to $\mathrm{C} / \mathrm{C}++$ for example, slows down the numerical calculation. This choice was made, however, since Python is a commonly known, flexible, easy to pick up by non-programmers, open-source and multi-platform language. It was also decided to limit the amount of code optimization to maintain its easy reading. Thus, whilst the calculation speed remains reasonable (in the order of minutes, depending on the discretization choices and the hardware used), it could be considered lacking efficiency especially considered complex, highly discretized problems. In those cases, combining python with another language (like $\mathrm{C}++$ ) could be interesting to gain in simulation time.

Despite these limitations, OM-MADE proposes an opensource solution to help a first analysis and simulation of multipeaked BTCs observed in karstic systems, which can be now used in any institution and location, and improved by everyone to fit their requirements.

\section{Author Contributions}

AJT wrote the numerical code, with a small contribution of PC for the structure and interface. PC initiated the collaboration, made the application to Furfooz (with contribution of AJT) and wrote the paper (with contributions of AJT, LD and VH). A first code version was developed and tested during CP master's project, advised by AJT and PC. LD and VH initiated the Furfooz study and provided the field data.

\section{ACKNOWLEDGEMENTS}

The authors acknowledge USGS and its developers for providing the inspiring OTIS software, as well as M. Field and F. Leij for providing the DADE. The authors are grateful to both the University of Lorraine (France) and the University of Namur (Belgium) for supporting this research. In particular, a part of this work has been financially supported by the program Widen Horizons of Lorraine Université d'Excellence (LUE). Finally, the authors wanted to thank both reviewers whose comments have helped them to improve not only the manuscript but also OMMADE itself.

\section{REFERENCES}

Bencala, K. E., 1983. Simulation of solute transport in a mountain pool-andriffle stream with a kinetic mass transfer model for sorption. Water Resources Research 19 (3), 732-738. (Cited page 1)

Bencala, K. E., Walters, R. A., 1983. Simulation of solute transport in a mountain pool-and-riffle stream: A transient storage model. Water Resources Research 19 (3), 718-724. (Cited pages 6 and 7)

Birk, S., Geyer, T., Liedl, R., Sauter, M., may 2005. Process-based interpretation of tracer tests in carbonate aquifers. Ground Water 43 (3), 381-388. (Cited page 2)

Bonniver, I., 2011. Etude hydrogéologique et dimensionnement par modélisation du "Système-Traçage" du réseau karstique de Han-sur-Lesse (Massif de Boine - Belgique). Ph.D. thesis, FUNDP Namur. (Cited pages 1 and 2)

Campbell, C., Sullivan, S. M., 2002. Simulating time-varying cave flow and water levels using the Storm Water Management Model. Engineering Geology 65 (2-3), 133-139. (Cited page 2)

Chen, Z., Goldscheider, N., 2014. Modeling spatially and temporally varied hydraulic behavior of a folded karst system with dominant conduit drainage at catchment scale, Hochifen-Gottesacker, Alps. Journal of Hydrology 514, 41-52. (Cited page 2)

Dewaide, L., 2018. Hydrodynamics of solute transport in karst conduits with contrasted geometries : karstogenesis description and tracer test modelling in the Wauslortian mudmounds (Furfooz, Belgium). Ph.D. thesis, University of Namur (Belgium). (Cited pages 7 and 9)

Dewaide, L., Baele, J.-M., Collon-Drouaillet, P., Quinif, Y., Rochez, G., Vandycke, S., Hallet, V., 2014. Karstification in dolomitized Waulsortian mudmounds (Belgium). Geologica Belgica 17 (1), 43-51. (Cited page 7)

Dewaide, L., Bonniver, I., Rochez, G., Hallet, V., 2016. Solute transport in heterogeneous karst systems: Dimensioning and estimation of the transport parameters via multi-sampling tracer-tests modelling using the OTIS (One-dimensional Transport with Inflow and Storage) program. Journal of Hydrology 534, 567-578. (Cited pages 1 and 2)

Dewaide, L., Collon, P., Poulain, A., Rochez, G., Hallet, V., 2018. Doublepeaked breakthrough curves as a consequence of solute transport through underground lakes: a case study of the Furfooz karst system, Belgium. Hydrogeology Journal 26 (2), 641-650. (Cited pages 1 and 7)

Field, M. S., 2002. The QTRACER2 program for tracer-breakthrough curve analysis for tracer tests in karstic aquifers and other hydrologic systems, us environ Edition. (Cited page 2)

Field, M. S., Leij, F. J., 2012. Solute transport in solution conduits exhibiting multi-peaked breakthrough curves. Journal of Hydrology 440-441, 26-35. (Cited pages 1, 2, 5, and 6)

Field, M. S., Pinsky, P. F., 2000. A two-region nonequilibrium model for solute transport in solution conduits in karstic aquifers. Journal of Contaminant Hydrology 44 (3-4), 329-351. (Cited page 2)

Galambos, P., Forster, F. K., 1998. Micro-fluidic diffusion coefficient measurement. Springer Netherlands, Dordrecht. (Cited page 3)

Geiser, J., 2010. Consistency of iterative operator-splitting methods: Theory and applications. Numerical Methods for Partial Differential Equations 26 (1), 135-158. (Cited pages 3 and 13)

Geyer, T., Birk, S., Licha, T., Liedl, R., Sauter, M., jan 2007. Multitracer test approach to characterize reactive transport in Karst aquifers. Ground Water 45 (1), 36-45. (Cited pages 2 and 9)

Goldscheider, N., Hötzl, H., Käss, W., Ufrecht, W., 2003. Combined tracer tests in the karst aquifer of the artesian mineral springs of Stuttgart, Germany. Environmental Geology 43 (8), 922-929. (Cited pages 1 and 2)

Goldscheider, N., Meiman, J., Pronk, M., Smart, C., 2008. Tracer tests in karst hydrogeology and speleology. International Journal of Speleology 37 (1), 27-40. (Cited pages 1 and 2)

Hauns, M., Jeannin, P.-Y., Atteia, O., 2001. Dispersion, retardation and scale effect in tracer breakthrough curves in karst conduits. Journal of Hydrology 241 (3-4), 177-193. (Cited pages 2 and 9)

Hauns, M., Jeannin, P. Y., Hermann, F., 1998. Tracer transport in karst underground rivers : tailing effect from channel geometry. Bulletin d'Hydrogéologie 16, 123-142. (Cited pages 1 and 2)

Hubbard, E., Kilpatrick, F., Martens, L., Wilson, J. J., 1982. Measurments of time of travel and dispersion in streams by dye tracing. In: USGS (Ed.), Techniques of Water-Resources Investigations, Book 3, Applications of Hydraulics. USGS, Washington, DC, Ch. A9, p. 44. (Cited page 1)

Hunter, J. D., 2007. Matplotlib: A 2D Graphics Environment. Computing in Science \& Engineering 9 (3), 90-95. (Cited page 15)

Jeannin, P.Y., Malard, A., Rickerl, D., Weber, E., 2015. Assessing karsthydraulic hazards in tunneling - the Brunnmühle spring system-Bernese Jura, Switzerland. Environmental Earth Sciences 74 (12), 7655-7670. (Cited page 2)

Käss, W., 1998. Tracing technique in geohydrology., CRC Press. ed (Cited page 2)

Kaufmann, G., Gabrovšek, F., Turk, J., 2016. Modelling flow of subterranean Pivka river in Postojnska jama, Slovenia. Acta Carsologica 45 (1). (Cited page 2)

Khan, L. A., Liu, P. L.-F., 1998. An operator splitting algorithm for the threedimensional advection-diffusion equation. International Journal for $\mathrm{Nu}$ merical Methods in Fluids 28 (3), 461-476. (Cited pages 3 and 13)

Knöll, P., Scheytt, T., 2017. A tracer test to determine a hydraulic connection between the Lauchert and Danube karst catchments (Swabian Alb, Germany). Hydrogeology Journal 26 (2), 429-437. (Cited page 1)

Lax, P., Wendroff, B., 1960. Systems of conservation laws. Communications on Pure and Applied mathematics 13 (2), 217-237. (Cited page 4)

Leij, F. J., Toride, N., 1995. Discrete time- and length-averaged solutions of the advection-dispersion equation. Water Resources Research 31 (7), 17131724. (Cited page 6)

Martin, J. L., McCutcheon, S. C., 1998. Hydrodynamics and transport for water quality modeling. CRC press. (Cited page 1) 
Maloszewski, P., Harum, T., Benischke, R., 1992. Mathematical modelling of tracer experiments in the karst of Lurbach system. Steirische Beiträge Zur Hydrogeologie 43, 116-136. (Cited page 2)

Massei, N., Wang, H. Q., Field, M. S., Dupont, J. P., Bakalowicz, M., Rodet, J., 2006. Interpreting tracer breakthrough tailing in a conduit-dominated karstic aquifer. Hydrogeology Journal 14 (6), 849-858. (Cited page 2)

Morales, T., Fdez. de Valderrama, I., Uriarte, J. A., Antigüedad, I., Olazar, M., 2007. Predicting travel times and transport characterization in karst conduits by analyzing tracer-breakthrough curves. Journal of Hydrology 334 (1-2), 183-198. (Cited page 1)

Morales, T., Uriarte, J. A., Olazar, M., Antigüedad, I., Angulo, B., 2010. Solute transport modelling in karst conduits with slow zones during different hydrologic conditions. Journal of Hydrology 390 (3-4), $182-189$. (Cited page 2)

Mudarra, M., Andreo, B., Marín, A. I., Vadillo, I., Barberá, J. A., 2014. Combined use of natural and artificial tracers to determine the hydrogeological functioning of a karst aquifer: the Villanueva del Rosario system (Andalusia, southern Spain). Hydrogeology Journal 22 (5), 1027-1039. (Cited page 1)

Perrin, J., Luetscher, M., 2008. Inference of the structure of karst conduits using quantitative tracer tests and geological information: example of the Swiss Jura. Hydrogeology Journal 16 (5), 951-967. (Cited page 1)

Peterson, E. W., Wicks, C. M., 2006. Assessing the importance of conduit geometry and physical parameters in karst systems using the storm water management model (SWMM). Journal of Hydrology 329, $294-305$. (Cited page 2)

Rossman, L. A., 2015. SWMM Stormwater Management Model user's manual Tech. rep., US Environmental Protection Agency, Cincinnati, Ohio (USA). (Cited page 2)

Runkel, R. L., 1996. Solution of the advection-dispersion equation: continuous load of finite duration. Journal of Environmental Engineering 122 (9), 830832. (Cited page 7)

Runkel, R. L., 1998. One-dimensional Transport with Inflow and Storage (OTIS): a solute transport model for streams and rivers. Tech. rep., USGS (Cited pages 1, 2, 6, and 7)

Sabatini, D. A., 2000. Sorption and intraparticle diffusion of fluorescent dyes with consolidated aquifer media. Ground Water 38 (5), 651-656. (Cited page 9)

Smart, C. C., 1988. Artificial tracer techniques for the determination of the structure of conduit aquifers. Ground Water 26 (4), 445-453. (Cited page 1)

Vuilleumier, C., 2018. Hydraulics and sedimentary processes in the karst aquifer of Milandre ( Jura Mountains, Switzerland). Ph.D. thesis, University of Neuchâtel, Switzerland. (Cited page 2)

Wu, Y., Jiang, Y., Yuan, D., Li, L., 2008. Modeling hydrological responses of karst spring to storm events: example of the Shuifang spring (Jinfo Mt., Chongqing, China). Environmental Geology 55 (7), 1545-1553. (Cited page 2)

Zheng, C., Wang, P. P., 1999. MT3DMS: a modular three-dimensional multispecies transport model for simulation of advection, dispersion, and chemical reactions of contaminants in groundwater systems; documentation and user's guide. Alabama University. (Cited pages 4, 5, and 10) 
The partial differential equation 2 that had to be solved for each zone $p$, requires temporal and spatial discretization schemes. Each reach is thus subdivided into discrete segments of length $d x$, referred to with the index $i$. In the OM-MADE software, two discretization schemes are made available to the end-user.

The first discretization scheme is based on an operator-split approach (sequential split) for the temporal discretization. The operator-split is a commonly used numerical method [Geiser, 2010, Khan and Liu, 1998] to allow the use of custom numerical solutions for distinct part of the equation. In our case, the equation is split sequentially between its hyperbolic part, the advection (represented by the operator $A_{a d v}$ in equations 7-8), and its parabolic part, the dispersion-exchange-reaction (represented by the operator $A_{d e r}$ in equations 7-8). This means that equation 2 , which could also be written as equation 7 (with $B$ being the part on equation 2 not dependent on the concentration), is replaced with the sub-problems shown in equation 8.

$$
\begin{gathered}
A \frac{\partial C}{\partial t}=A_{a d v} C+A_{d e r} C+B \\
\begin{cases}\frac{\partial C^{*}}{\partial t}=A_{a d v} C^{*} & \text { with } C^{*[t]}=C^{[t]} \\
\frac{\partial C^{* *}}{\partial t}=A_{d e r} C^{* *}+B & \text { with } C^{* *[t]}=C^{*[t+d t]}=C^{\left[t^{\prime}\right]}\end{cases}
\end{gathered}
$$

The approximated solution is then $C^{[t+d t]}=C^{* *[t+d t]}$. The advective part is solved using the second order - in time and space - Lax-Wendroff scheme with explicit temporal resolution (equation 9).

$$
\frac{C^{\left[t^{\prime}, i\right]}-C^{[t, i]}}{d t}=-\frac{Q}{A_{i}}\left(\frac{C^{[t, i+1]}-C^{[t, i-1]}}{d x}\right)+\frac{d t}{2} \frac{Q^{2}}{A_{i}}\left(\frac{C^{[t, i+1]}-2 C^{[t, i]}+C^{[t, i-1]}}{d x^{2}}\right)
$$

In such conditions, the Lax-Wendroff scheme is conditionally stable. A necessary condition is the Courant-Friedrichs-Lewy (CFL) that constrains the grid Courant number (equation 10).

$$
\left|\frac{Q d t}{A d x}\right| \leq 1
$$

When the time step following the CFL condition (later named advection step) is lower that the desired time step $d t$, sublooping of the advection solution is required until reaching the desired time step. In the OM-MADE software, the advection is independent for each channel, therefore the advection step may be computed independently. However, this value may be dependent on space when different reaches with different surfaces occur or when lateral flows are involved. In this case, the most constraining value for the advection step should be used for the whole channel.

The dispersion-exchange-reaction part is solved using a second order - in space - scheme with implicit temporal solution (equation 11). The implicit scheme is unconditionally stable, therefore does not require sub-looping and may be used with large time steps. However, the implicit approach requires a linear system resolution, thus a higher numerical cost.

$$
\begin{array}{r}
\frac{C^{[t+1, i]}-C^{\left[t^{\prime}, i\right]}}{d t}=\frac{(A D)_{i+\frac{1}{2}}\left(C^{[t+1, i+1]}-C^{[t+1, i]}\right)-(A D)_{i-\frac{1}{2}}\left(C^{[t+1, i]}-C^{[t+1, i-1]}\right)}{(A)_{i} d x^{2}} \\
+\left(\frac{q_{i n}}{A}\right)_{i}\left(\left(C_{i n}\right)_{i}-C^{[t+1, i]}\right)+\sum_{q \neq p}\left(\frac{\alpha_{q p}}{A}\right)_{i}\left(C_{q}^{[t+1, i]}-C^{[t+1, i]}\right)-(\lambda)_{i} A C^{[t+1, i]}
\end{array}
$$

The second discretization scheme is similar to the one used in OTIS. It is based on a second order - in time and space resolution. The temporal scheme is the Crank-Nicholson pondered scheme and the spatial resolution for the advection part is the centred scheme as shown in equations (12-13).

$$
\begin{gathered}
f(t, i)=-\left(\frac{Q}{A}\right)_{i} \frac{C^{[t, i+1]}-C^{[t, i-1]}}{2 d x}+\frac{(A D)_{i+\frac{1}{2}}\left(C^{[t, i+1]}-C^{[t, i]}\right)-(A D)_{i-\frac{1}{2}}\left(C^{[t, i]}-C^{[t, i-1]}\right)}{(A)_{i} d x^{2}} \\
+\left(\frac{q_{i n}}{A}\right)_{i}\left(\left(C_{i n}\right)_{i}-C^{[t, i]}\right)+\sum_{q \neq p}\left(\frac{\alpha_{q p}}{A}\right)_{i}\left(C_{q}^{[t, i]}-C^{[t, i]}\right)-(\lambda)_{i} A C^{[t, i]} \\
\frac{C^{[t+1, i]}-C^{[t, i]}}{d t}=\frac{1}{2}(f(t+d t, i)+f(t, i))
\end{gathered}
$$

It should be noted that the flowrate is calculated at each position using the analytical solution of equation 1 . These equations are solved for each time-step and each segment of each zone. An average concentration $C_{a v}$ can be computed, if wanted, for each location $x$ and each time-step $t$ as a weighted sum of each zone :

$$
C_{a v}(x, t)=\frac{\sum_{p} C_{p} Q_{p}}{\sum_{p} Q_{p}}
$$




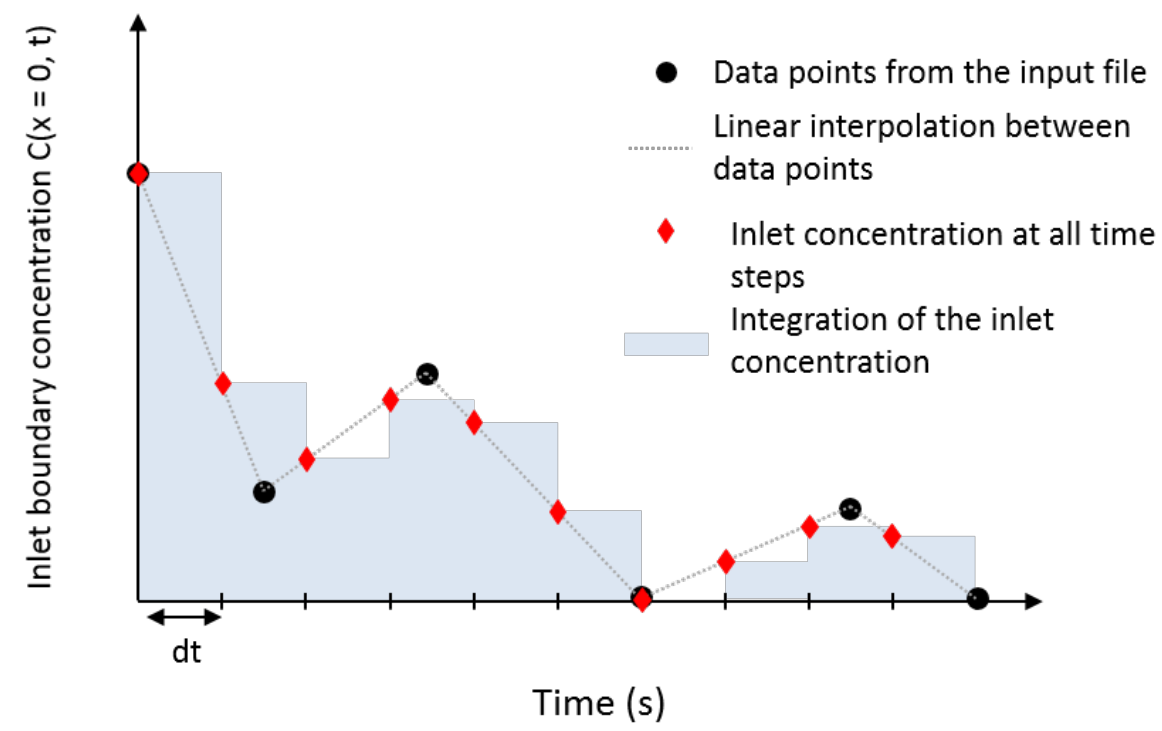

Figure 10 Boundary conditions: the input concentration is computed by a linear interpolation between the successive values provided by the user.

But it is only meaningful in locations where all zones are considered to be mixed.

Solving the partial differential equations 2 describing the concentration evolution in each zone requires to specify initial and boundary conditions. At the inlet, a time-dependent imposed concentration conditions each zone. Therefore, both continuous and step-wise tracer injection can be simulated. A Dirac injection can be approximated by imposing concentration at onetime step only. When an inlet boundary condition is not explicitly given in the input data file, its value is computed by linear interpolation (Fig. 10). The total mass $M$ injected at the inlet along the simulation and for all zones may be calculated using equation 15, given that the concentration $\mathrm{Cp}$ in unit of mass per unit of volume. Boundary condition at the outlet corresponds to a zero diffusive flux condition. At initial step, a constant concentration is imposed in all reaches for each zone.

$$
M=\sum_{p=\text { mobile }} \int_{t_{0}}^{t_{\max }} C_{p}(x=0, t) Q_{p} \delta t
$$




\section{APPENDIX B: DESCRIPTION OF THE SOFTWARE ARCHITECTURE}

OM-MADE is written in Python v3. We chose this high-level interpreted language because it allows rapid developments and is easy to pick up by non-programmers. Python is open-source, multi-platform and allows functional and object-oriented programming. Several powerful libraries have been developed that allow to directly use optimised and verified algorithms for matrix manipulations, scientific computation or result visualisation. In OM-MADE, we use numpy (http://numpy.scipy.org) to solve linear systems, and matplotlib [Hunter, 2007] is used in some examples of main programs to directly visualize the results of a simulation.

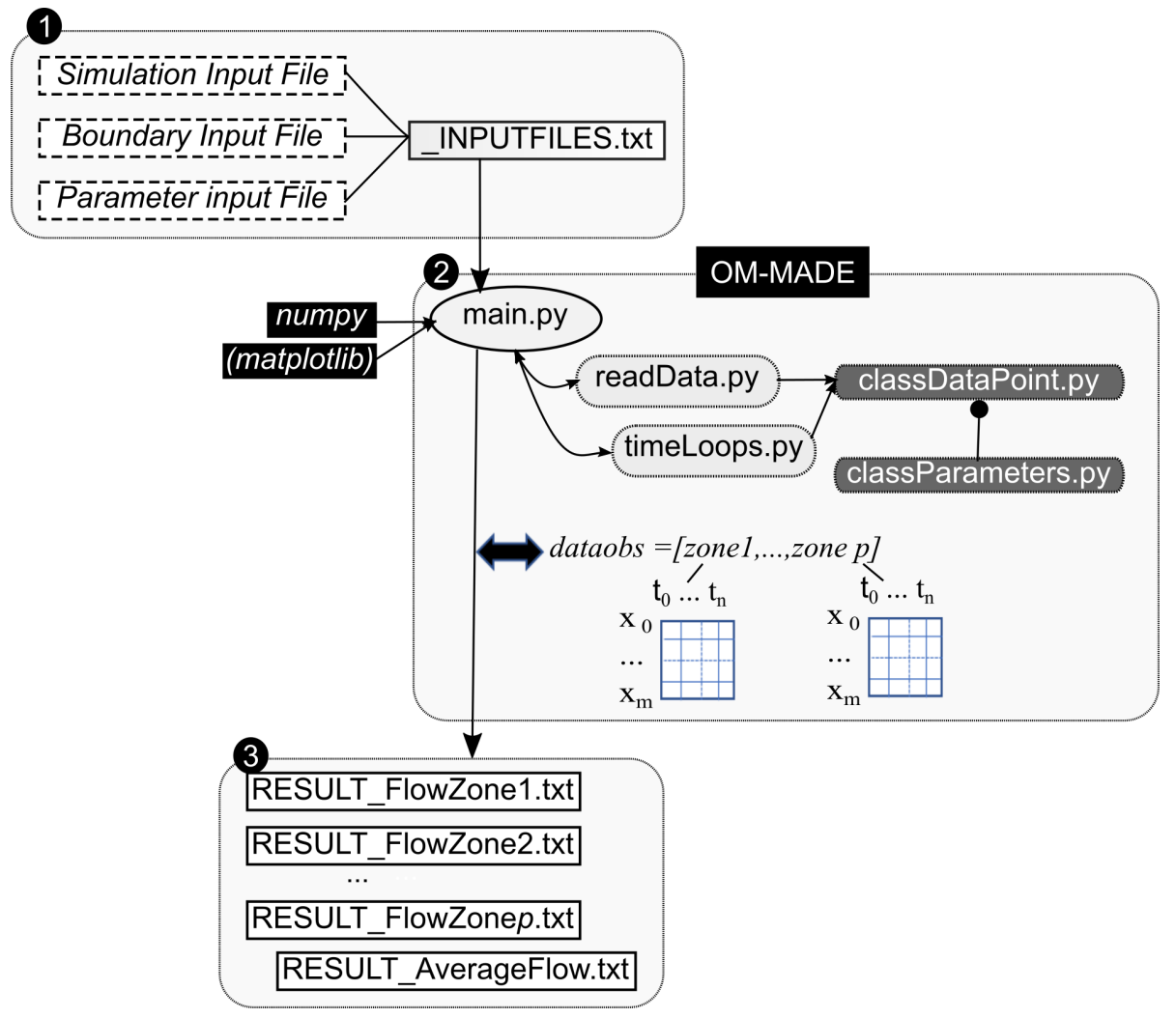

Figure 11 OM-MADE architecture: Three text input files are required by the INPUTFILES.txt file (1). They contain all information to run a specific simulation. OM-MADE (2) should be launched by running the main program (several examples are provided), which calls four python modules. The result of a simulation is stored in the dataobs variable, which is a list of arrays containing, for each zone, the concentration for each printed time and distance. This variable can be used to generate several text files containing the result of the simulation (3)).

The program is divided into four modules - all reusable in any other Python program - that are called by an independent file containing the main program (Fig. 11). In the package, different specific examples of main programs are given, which exploit directly the possibilities of a direct result visualization thanks to matplotlib, as well as a generic main program. The generic main program reads an INPUTFILES.txt text file, which should contain the path and names of the different input parameter files. Three input parameter files are required: (i) one describing the simulation parameters (chosen scheme, spatial step, time step, initial concentration, printing locations, and printing times), (ii) one for boundary conditions (input concentration through time for each zone), and (iii) one describing zone and reach characteristics (length, area, dispersion coefficient, degradation/adsorption rate, lateral in and outflow rates, lateral inflow concentration, and exchange coefficients). As output of the simulation, it produces one file per flow zone containing the concentration through time at the printing locations, and the corresponding time steps in the first column. An additional output file RESULT_AverageFlow.txt contains also the corresponding average concentration for all mobile zones (Eq. 14) at each printing location.

Two classes are defined in two modules : (i) the class Parameters defines all physical parameters for one zone and reach of the domain; (ii) the class DataPoint contains the physical data required for computation on one point (flow type and location) of the domain. It defines, punctually, the calculation of advection, dispersion, mass exchange between two flow types co-located points and mass exchange through either degradation/adsorption or lateral flow.

These classes are used by the functions implemented in the readData and timeLoops modules. The first module gathers functions that permit the reading and storage of the simulation parameters from the input text files. The second one initialises the concentration and does the overall loop (advection, and then dispersion) for each time step, until reaching the total simulation time. It returns a matrix containing the concentration for each printing location at each printing time step. In the operator-split scheme, the sub-looping of the advection is performed in the function advectionLoop.

The OM-MADE package is freely available on GitHub as a Python project (https: / / g i thub . com/OM-MADE / OM-MADE). It is provided with examples of applications on the following verification case studies (Section 3), as well as an application on the Furfooz karstic area (Section 4). 